\title{
Decision Tree-based Modelling for Identification of Predictors of Blood Loss and Transfusion Requirement After Adult Spinal Deformity Surgery
}

\author{
TINA RAMAN, MD, DENNIS VASQUEZ-MONTES, MS, CHRIS VARLOTTA, BS, PETER G. PASSIAS, MD, \\ THOMAS J. ERRICO, MD \\ Department of Orthopaedic Surgery, NYU Langone Orthopedic Hospital, New York, New York
}

\begin{abstract}
Background: Multilevel fusions and complex osteotomies to restore global alignment in adult spinal deformity (ASD) surgery can lead to increased operative time and blood loss. In this regard, we assessed factors predictive of perioperative blood product transfusion in patients undergoing long posterior spinal fusion for ASD.

Methods: A single-institution retrospective review was conducted on 909 patients with ASD, age $>18$ years, who underwent surgery for ASD with greater than 4 levels fused. Using conditional inference tree analysis, a machine learning methodology, we sought to predict the combination of variables that best predicted increased risk for intraoperative percent blood volume lost and perioperative blood product transfusion.

Results: Among the 909 patients included in the study, 377 (41.5\%) received red blood cell (RBC) transfusion. The conditional inference tree analysis identified greater than 13 levels fused, American Society of Anesthesiologists (ASA) score $>1$, a history of hypertension, 3-column osteotomy, pelvic fixation, and operative time $>8$ hours, as significant risk factors for perioperative RBC transfusion. The best predictors for the subgroup with the highest risk for intraoperative percent blood volume lost (subgroup mean: $53.1 \% \pm 42.9 \%$ ) were greater than 13 levels fused, ASA score $>1$, preoperative hemoglobin $<13.6 \mathrm{~g} / \mathrm{dL}, 3$-column osteotomy, posterior column osteotomy, and pelvic fixation. Patients who underwent major blood transfusion intraoperatively had significantly longer length of stay $(8.5$ days) versus those who did not $(6.1$ days $)(P<.0001)$. The overall 90-day complication rate in patients who underwent major blood transfusion intraoperatively was $49 \%$, compared with $19 \%$ in those who did not $(P<.0001)$. By multivariate regression analysis, patients with a preoperative hemoglobin $>13.0$ were less likely to require major blood transfusion (odds ratio: $0.52, P=.046$ ).

Conclusions: Using a supervised learning technique, this study demonstrates that greater than 13 levels fused, ASA score > 1,3-column osteotomy, and pelvic fixation are consistent risk factors for increased intraoperative percent blood volume lost and perioperative $\mathrm{RBC}$ transfusion. The addition of having a preoperative hemoglobin $<13.6 \mathrm{~g} / \mathrm{dL}$ or undergoing a posterior column osteotomy conferred the highest risk for intraoperative blood loss. This information can assist spinal deformity surgeons in identifying at-risk individuals and allocating healthcare resources.
\end{abstract}

Level of Evidence: 3.

Complications

Keywords: perioperative blood loss, blood product transfusion, complex spine surgery

\section{INTRODUCTION}

Blood loss requiring significant transfusion requirement is often associated with multilevel fusion for adult spinal deformity (ASD). Surgical factors including number of vertebral levels incorporated in the fusion, duration of exposure, patient position, blood pressure, and spinal osteotomies and complex realignment procedures performed, are recognized risk factors for increased intraoperative bleeding. ${ }^{1-4}$ Patient factors that have been elucidated include classification and severity of the spinal deformity, as well as patient age, height, weight, and preoperative comorbidities. 5,6

Although red blood cell (RBC) transfusion is perhaps safer than it ever has been, it still may be associated with adverse events including transfusion reaction, transfusion-related lung injury, postoperative complications, and infection. ${ }^{7-10}$ There is growing evidence that blood transfusion may increase intensive care unit and overall length of hospital stay, as well as increase mortality. ${ }^{11,12}$ Although the associations described in the literature do not constitute causality, most deformity surgeons 
universally agree that minimizing blood loss and transfusion requirement is a key tenet of successful surgery. In an era of increased focus on healthcare expenditures, it is also impossible to overlook the direct cost of 1 unit of RBC in the United States, which ranges from 700 to 1200 dollars, and the resulting economic impact. ${ }^{13}$ Anticipating blood loss a priori in patients at known high risk for blood loss is critical for optimal preoperative transfusion planning, and potential employment of surgical strategies such as antifibrinolytic use and intraoperative cell salvage devices to reduce utilization of allogeneic blood. ${ }^{14-18}$

Although studies have evaluated the adult spine surgical population as a whole, with regards to predictors for blood loss and transfusion, such a population is relatively heterogenous in its composition of patient characteristics and surgical procedures formed. Previous studies have looked at only parts of the puzzle, assessing a subset of variables that may be related to blood loss in adult deformity surgery, or utilizing cohorts of patients with incomplete data. Although regression models have been the benchmark to detect main effects, proper assessment of the interactions between risk factors can significantly increase the number of potential models, making model selection more problematic. ${ }^{19}$ Further, it is our experience that surgeons often intuitively want to classify patients into high or low risk, rather than deploy risk ratios generated by regression methods.

To that end, we sought to predict intraoperative blood loss and perioperative RBC transfusion using machine learning methods, specifically conditional inference tree analysis. ${ }^{20,21}$ The primary objective of this study is to determine predictive factors associated with blood loss and transfusion in a large and relatively homogenous cohort of patients with ASD from a single institution, multisurgeon database. Secondarily, we used conditional inference tree analysis to identify and characterize combinations of variables that best predict highest risk for intraoperative blood loss and perioperative RBC transfusion, and to define cutoff values for these variables when possible.

\section{MATERIALS AND METHODS}

We retrospectively reviewed our institution's prospectively collected database to identify patients who were aged 18 years or older when they underwent posterior spinal fusion (PSF) for ASD, with a minimum of 4 levels fused, from January 2012 through December 2017. We identified 909 such patients with complete surgical and inpatient admission data.

\section{Patient and Surgical Characteristics}

The primary indications for surgery were scoliosis or kyphosis with pain and disability for which prolonged nonoperative treatment had failed. We used the clinical database and patients' medical records to ascertain patient characteristics including age, sex, and American Society of Anesthesiologists (ASA) score. Based on a validated 5-item frailty index, a modified frailty index (mFI) was calculated for each patient, with 5 categories of frailty ranging from 1 (lowest) to 5 (highest). ${ }^{22,23}$

Surgical parameters collected included number of levels fused, the use of pelvic fixation, interbody fusion, and multirod construct. Each case was assigned a Mirza invasiveness index, based on published criteria, for the purposes of assessing surgical complexity between the 2 groups. ${ }^{24,25}$

\section{Blood Loss and Transfusion Requirement}

The primary outcomes assessed were estimated blood loss (EBL; mL), EBL per vertebral level fused, percent blood volume loss, and perioperative transfusion requirement (units of RBCs, platelets, fresh-frozen plasma [FFP]). Preoperative, intraoperative, and postoperative hemoglobin levels $(\mathrm{g} / \mathrm{dL})$ were included in the analysis. Postoperative complications, length of hospital stay, reoperations, and mortality were assessed within 90 days of the index surgery.

\section{Statistical Analysis}

The 2 groups were compared with the $t$ test statistic or Mann-Whitney nonparametric statistic for continuous parameters. Chi-square tests were used for categorical data when all the expected counts had 5 or more observations, and Fisher exact tests were used for categorical data when any of the expected counts had fewer than 5 observations. Univariate analysis was performed for all possible determinants of $\mathrm{RBC}$ transfusion. We defined, a priori, that all variables with a $P$ value less than 0.05 by univariate analysis were considered relevant and included in the stepwise multivariate logistic regression analysis. This second analysis was used to 
Table 1. Demographic data for 909 adults who underwent surgery for spinal deformity.

\begin{tabular}{|c|c|c|c|c|c|}
\hline \multirow[b]{2}{*}{ Characteristic } & \multicolumn{2}{|c|}{ Not Transfused $(\mathrm{N}=532)$} & \multicolumn{2}{|c|}{ Transfused $(\mathrm{N}=377)$} & \multirow[b]{2}{*}{$P$ Value } \\
\hline & $\mathbf{N}$ & $\%$ & $\mathbf{N}$ & $\%$ & \\
\hline Age, $\mathrm{y}^{\mathrm{a}}$ & \multicolumn{2}{|c|}{$36.4 \pm 23.0$} & \multicolumn{2}{|c|}{$54.8 \pm 20.2$} & $<.0001$ \\
\hline $\mathrm{BMI}$ & $24 \pm 6$ & & $26 \pm 7$ & & $<.0001$ \\
\hline ASA score & $2.3 \pm 0.7$ & & $2.5 \pm 0.6$ & & .004 \\
\hline $\mathrm{mFI}$ & $0.3 \pm 0.6$ & & $0.5 \pm 0.7$ & & $<.0001$ \\
\hline Preoperative hemoglobin, $\mathrm{g} / \mathrm{dL}$ & $13.9 \pm 1.4$ & & $13.3 \pm 1.5$ & & $<.0001$ \\
\hline Female sex & 328 & 61.7 & 281 & 74.5 & $<.0001$ \\
\hline \multicolumn{6}{|l|}{ Comorbidities } \\
\hline Diabetes & 29 & 5.5 & 36 & 9.5 & .02 \\
\hline COPD & 16 & 3.0 & 22 & 5.8 & .04 \\
\hline Cardiovascular disease & 19 & 3.6 & 31 & 8.2 & .001 \\
\hline Osteoporosis & 21 & 3.9 & 43 & 11.4 & $<.0001$ \\
\hline
\end{tabular}

${ }^{\mathrm{a}}$ Expressed as mean \pm standard deviation.

define factors that were able to predict $\mathrm{RBC}$ transfusion in adults undergoing ASD surgery.

Next, we used conditional inference tree analysis, a machine learning method, to predict blood loss and perioperative RBC transfusion. Briefly, conditional inference tree analysis is a data mining tool that recursively splits a data set into smaller subsets, with each split made by defining a cutoff value of one of $\mathrm{n}$ number of predictors, based on observations viewed as points in an n-dimensional space. As multiple predictors were considered, Tukey Honest Significant Difference (HSD) correction was used to counteract the problem of multiple comparisons.

Descriptive statistics were calculated with SPSS version 25 software (IBM, Armonk, NY), R statistical software, and Microsoft Office Excel software (Microsoft Corp, Redmond, WA).

\section{RESULTS}

\section{Patient Population}

Included in the study were 909 adults (222 women) who underwent surgery for ASD. Three hundred seventy-seven patients $(41.5 \%)$ received an intraoperative RBC transfusion, "transfused" group, and 532 patients $(58.5 \%)$ constituted the "not transfused" group. There were multiple significant differences found between the transfused and not transfused groups, with regards to preoperative characteristics. The mean patient age in the transfused group $(54.8 \pm 20.2$ years $)$ was significantly higher than in the not transfused group $(36.4 \pm 23.0$ years) $(P<.0001)$. Patients in the transfused group were more commonly female, and had significantly higher body mass index (BMI), ASA score, frailty index ( $\mathrm{mFI}$ score), and had a greater incidence of diabetes, cardiovascular disease, chronic obstructive pulmonary disease (COPD), and osteoporosis. The mean preoperative hemoglobin in the transfused group was $13.3 \pm 1.4 \mathrm{~g} / \mathrm{dL}$, which was significantly lower than in the not transfused group, $13.9 \pm 1.5$ $\mathrm{g} / \mathrm{dL}(P<.0001)$. There was no difference in utilization of intraoperative cell salvage between the transfused and not transfused groups. Full demographic data for the study population are presented in Table 1.

\section{Surgical Characteristics}

Patients who received transfusion more commonly underwent cases with a higher Mirza invasiveness index, greater number of levels fused, and of greater surgical duration $(P<.0001$ for all). Surgical procedures in the transfused group more commonly incorporated the use of pelvic fixation, transforaminal lumbar interbody fusion (TLIF), osteotomies, and multi-rod constructs. Patients who received transfusion were also more likely to have a significantly longer length of hospital stay, and more commonly required unplanned return to the operating room within 90 days of index surgery. See Table 2 for complete surgical characteristics of the 2 groups.

\section{Predictors of Percent Blood Volume Lost and Perioperative RBC Transfusion by Multivariate Regression Analysis}

All variables found to be associated with increased intraoperative blood loss and perioperative $\mathrm{RBC}$ transfusion by univariate analysis were included in the multivariate regression analysis. We observed that significant predictors of percent blood volume lost were number of levels fused, 3-column osteotomy, posterior column osteotomy in the lumbar spine, and pelvic fixation (Table 3). 
Table 2. Surgical characteristics for 909 adults who underwent surgery for spinal deformity.

\begin{tabular}{|c|c|c|c|c|c|}
\hline \multirow[b]{2}{*}{ Parameter } & \multicolumn{2}{|c|}{ Not Transfused $(\mathrm{N}=\mathbf{5 3 2})$} & \multicolumn{2}{|c|}{ Transfused $(\mathrm{N}=377)$} & \multirow[b]{2}{*}{$P$ Value } \\
\hline & $\mathbf{N}(\%)$ & Mean & $\mathbf{N}(\%)$ & Mean & \\
\hline $\mathrm{EBL}, \mathrm{mL}$ & & $894 \pm 752$ & & $2377 \pm 1736$ & $<.0001$ \\
\hline $\mathrm{EBL} /$ vertebral level fused, $\mathrm{mL}$ & & $115 \pm 106$ & & $237 \pm 232$ & $<.0001$ \\
\hline Percent blood volume lost, \% & & $18.8 \pm 15.2$ & & $50.7 \pm 35.5$ & $<.0001$ \\
\hline Intraoperative cell salvage, $\mathrm{U}$ & & $0.46 \pm 0.91$ & & $2.2 \pm 2.4$ & $<.0001$ \\
\hline Mirza invasiveness index & & $18.0 \pm 7.6$ & & $23.8 \pm 8.4$ & $<.0001$ \\
\hline Number of levels fused & & $8.9 \pm 3.8$ & & $11.5 \pm 4.3$ & $<.0001$ \\
\hline Surgical duration, $\mathrm{h}$ & & $5.9 \pm 2.4$ & & $7.4 \pm 4.4$ & $<.0001$ \\
\hline Pelvic fixation & $85(16)$ & & $203(54)$ & & $<.0001$ \\
\hline 3-column osteotomy & $34(6)$ & & $83(22)$ & & $<.0001$ \\
\hline Posterior column osteotomy & $160(30)$ & & $219(58)$ & & $<.0001$ \\
\hline TLIF & $91(17)$ & & $167(44)$ & & $<.0001$ \\
\hline ALIF & $14(3)$ & & $18(5)$ & & .08 \\
\hline Tranexamic acid use & $183(34)$ & & $206(55)$ & & $<.0001$ \\
\hline Multirod $(>2)$ configuration & $16(3)$ & & $44(12)$ & & $<.0001$ \\
\hline Length of hospital stay, $d$ & & $5.6 \pm 4.0$ & & $7.4 \pm 3.9$ & $<.0001$ \\
\hline Unplanned return to operating room & $21(4)$ & & $46(12)$ & & $<.0001$ \\
\hline
\end{tabular}

Abbreviations: ALIF, anterior lumbar interbody fusion; TLIF, transforaminal lumbar interbody fusion.

Age, ASA score, a history of hypertension, pelvic fixation, number of levels fused, performance of a 3column osteotomy, and operative time were independently associated with intraoperative RBC transfusion in the study population (Table 4). Pelvic fixation was associated with a mean of 0.5 additional units of RBCs transfused intraoperatively $(P<.0001)$, and performance of a 3 -column osteotomy was associated with a mean of 0.7 additional units of RBCs transfused intraoperatively $(P<.0001)$. Pelvic fixation, ASA score, and number of levels fused were independently associated with postoperative RBC transfusion.

\section{Predictors of Percent Blood Volume Lost and Perioperative RBC Transfusion by Conditional Interference Tree Analysis}

Conditional inference tree analysis was used to identify which variables, or combination of variables, were best suited to predict increased intraoperative blood loss and perioperative RBC transfusion. Of the predictors that were examined for percent blood volume lost, the analysis identified number of levels fused (splitting at 6 and 13 levels), pelvic fixation, ASA score (splitting at 1), 3-column osteotomy, posterior column osteotomy, and pre-

Table 3. Determinants of percent blood volume lost

\begin{tabular}{lcc}
\hline Parameter & $\begin{array}{c}\boldsymbol{\beta} \text { Coefficient } \\
(\mathbf{9 5 \%} \mathbf{C I})\end{array}$ & $\boldsymbol{P}$ Value \\
\hline Number of levels fused & $1.9(0.02$ to 0.03$)$ & $<.0001$ \\
3-column osteotomy & $16.8(0.01$ to 0.07$)$ & $<.0001$ \\
Lumbar posterior column & $9.2(-1.5$ to -0.5$)$ & .005 \\
$\quad \begin{array}{l}\quad \text { osteotomy } \\
\text { Pelvic fixation }\end{array}$ & $11.3(0.002$ to 0.004$)$ & $<.0001$ \\
\hline
\end{tabular}

operative hemoglobin (splitting at $13.6 \mathrm{~g} / \mathrm{dL}$ ) as significant risk factors for increased blood loss. See Figure 1 for full description of conditional inference tree nodes as well as incremental percent blood volume lost added by each risk factor.

Of the predictors that were examined for intraoperative RBC transfusion, the analysis identified number of levels fused (splitting at 13 levels), pelvic fixation, ASA score (splitting at 1), 3-column osteotomy, posterior column osteotomy, hypertension, preoperative hemoglobin (splitting at $13.6 \mathrm{~g} /$ $\mathrm{dL}$ ), and surgical duration (splitting at 8 hours) as significant risk factors for increased volume of intraoperative RBC units transfused. See Figure 2 for full description of conditional inference tree nodes as well as incremental units of intraoperative RBCs added by each risk factor.

Of the predictors that were examined for postoperative RBC transfusion, the analysis identified number of levels fused (splitting at 13 levels), pelvic fixation, ASA score (splitting at 2), age (splitting at 65 years), and surgical duration (splitting at 6 hours) as significant risk factors for increased volume of postoperative RBC units transfused. See Figure 3

Table 4. Determinants of intraoperative packed RBC transfusion.

\begin{tabular}{lcc}
\hline Parameter & $\boldsymbol{\beta}$ Coefficient $(\mathbf{9 5 \%} \mathbf{C I})$ & $\boldsymbol{P}$ Value \\
\hline Pelvic fixation & $0.52(0.02$ to 0.03$)$ & $<.0001$ \\
ASA score & $0.33(0.01$ to 0.07$)$ & $<.0001$ \\
Number of levels & $0.09(0.002$ to 0.004$)$ & $<.0001$ \\
Age & $0.007(0.15$ to 1.3$)$ & .047 \\
3-column osteotomy & $0.73(-1.5$ to -0.5$)$ & $<.0001$ \\
Operative time & 0.001 & .007 \\
TLIF & 0.37 & .007 \\
History of hypertension & 0.33 & .02 \\
\hline
\end{tabular}




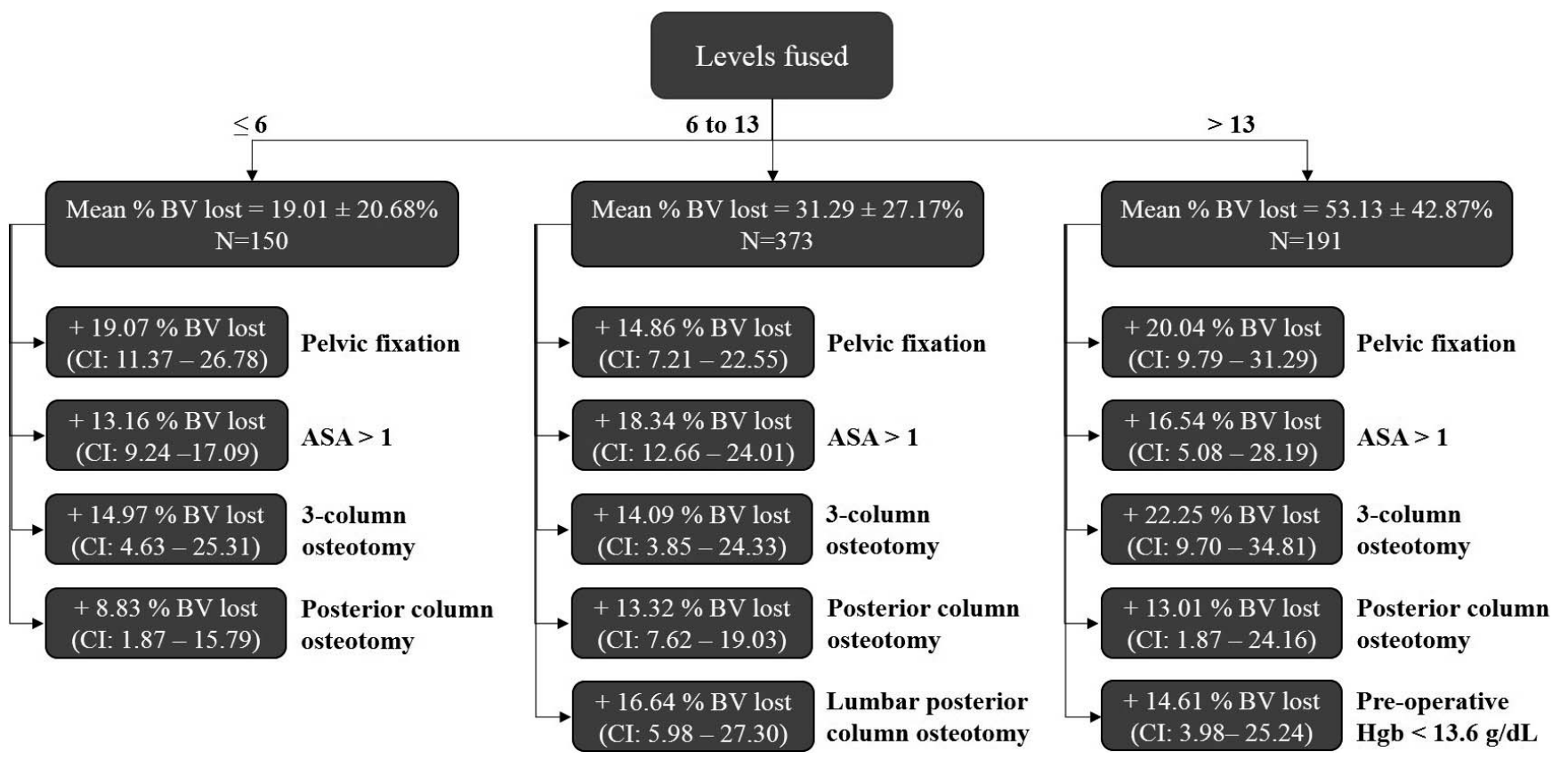

Figure 1. Classification and decision tree model for intraoperative percent blood volume (BV) lost in different risk groups of patients who underwent surgery for ASD. Performance measures: $\leq 6$ levels: $R^{2-A d j}=0.58 ; 6$ to 13 levels: $R^{2-A d j}=0.51 ;>13$ levels: $R^{2-A d j}=0.64$.

for full description of conditional inference tree nodes as well as incremental units of postoperative $\mathrm{RBCs}$ added by each risk factor.

\section{Major Blood Loss (Intraoperative Transfusion $>4$ $\mathrm{U} \mathrm{RBC})$}

Patients who received major blood transfusion intraoperatively, as defined by $>4 \mathrm{U}$ RBCs $(10.8 \%$ of all patients), were significantly older (60.2 vs 41.8 years), had higher ASA (2.6 vs 2.4), underwent greater number of levels fused (13.2 vs 9.6), and had lower preoperative hemoglobin (13.1 vs 13.7)

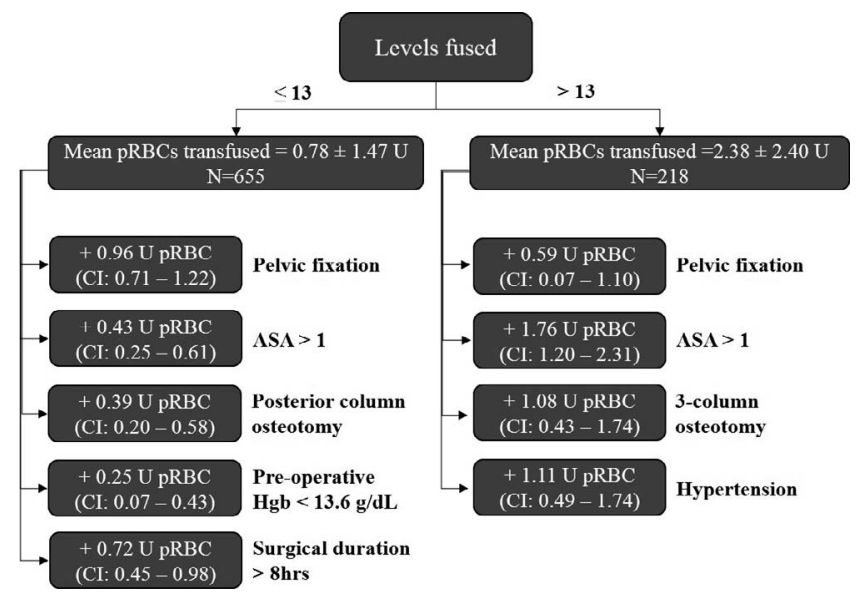

Figure 2. Classification and decision tree model for intraoperative RBCs transfused in different risk groups of patients who underwent surgery for ASD. Performance measures: $\leq 13$ levels: $R^{2-A d j}=0.43 ;>13$ levels: $R^{2 \text {-Adj }}=0.59$.
$(P<.0001$ for all). They more commonly underwent pelvic fixation (74\% vs $26.5 \%, P<.0001)$, 3 column osteotomy (42\% vs 9\%, $P<.0001)$, Smith Peterson osteotomy $(67 \%$ vs $39 \%, P<.0001)$, interbody fusion $(59 \%$ vs $25 \%, P<.001)$, and had multi-rod constructs $(24 \%$ vs $4 \%, P<.0001)$. Patients who underwent major blood transfusion intraoperatively had significantly longer length of stay (8.5 days) versus those who did not (6.1 days) $(P<.0001)$. The overall 90 -day complication rate in patients who underwent major blood transfusion intraoperatively was $49 \%$, compared with $19 \%$ in those who did not $(P<.0001)$. By multivariate regression analysis, patients with a preoperative

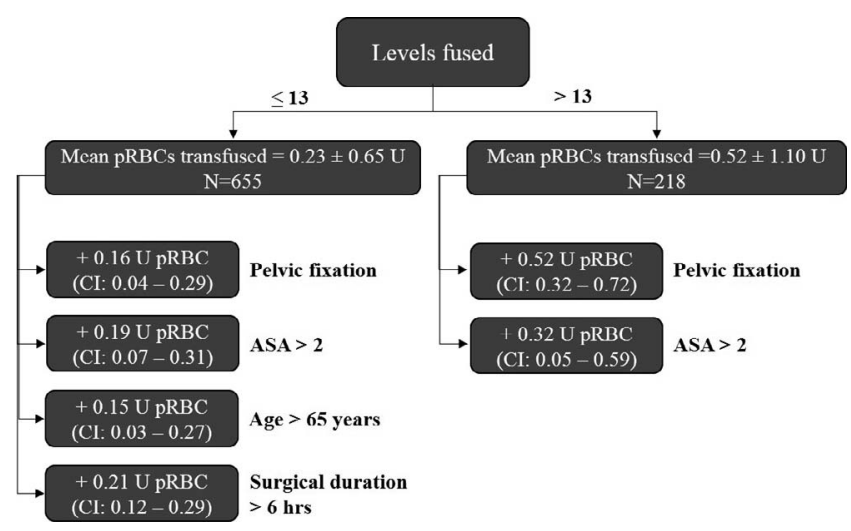

Figure 3. Classification and decision tree model for units of postoperative RBCs transfused in different risk groups of patients who underwent surgery for ASD. Performance measures: $\leq 13$ levels: $R^{2-A d j}=0.41 ;>13$ levels: $R^{2-A d j}=0.45$. 
Table 5. Complications in 909 adults who underwent surgery for spinal deformity.

\begin{tabular}{|c|c|c|c|c|c|}
\hline \multirow[b]{2}{*}{ Parameter } & \multicolumn{2}{|c|}{ Not Transfused $(\mathrm{N}=532)$} & \multicolumn{2}{|c|}{ Transfused $(\mathbf{N}=377)$} & \multirow[b]{2}{*}{$P$ Value } \\
\hline & $\mathbf{N}$ & $\%$ & $\mathbf{N}$ & $\%$ & \\
\hline Sepsis & 0 & 0 & 3 & 0.8 & .11 \\
\hline Wound infection & 17 & 3.2 & 23 & 6.1 & .67 \\
\hline Seroma & 12 & 2.3 & 17 & 4.5 & .63 \\
\hline Respiratory failure & 0 & 0 & 0 & 0 & - \\
\hline Delirium & 1 & 0.2 & 3 & 0.8 & .40 \\
\hline Postoperative atrial fibrillation & 2 & 0.4 & 0 & 0 & .23 \\
\hline STEMI & 0 & 0 & 2 & 0.5 & .09 \\
\hline DVT & 1 & 0.2 & 5 & 1.3 & .16 \\
\hline PE & 1 & 0.2 & 7 & 2.0 & .06 \\
\hline Postoperative pneumonia & 2 & 0.4 & 4 & 1.1 & .54 \\
\hline Stroke & 0 & 0 & 1 & 0.3 & .36 \\
\hline Ileus & 1 & 0.2 & 10 & 2.7 & .02 \\
\hline Urinary retention & 0 & 0 & 4 & 1.1 & .81 \\
\hline Epidural hematoma & 1 & 0.2 & 1 & 0.3 & .90 \\
\hline Mortality & 1 & 0.2 & 3 & 0.8 & .40 \\
\hline
\end{tabular}

Abbreviations: STEMI, ST-elevation myocardial infarction; DVT, deep vein thrombosis; PE, pulmonary embolism.

hemoglobin $>13.0 \mathrm{~g} / \mathrm{dL}$ were less likely to require major blood transfusion (OR: 0.52, $P=.046$ ).

\section{Adverse Events}

There was no significant difference in wound infection, thromboembolic event, cardiac or ischemic events, or epidural hematoma between the transfused and not transfused groups (Table 5). The rate of wound infection was $6.1 \%$ in the transfused group, and $3.2 \%$ in the not transfused group $(P=.67)$. The incidence of ileus was significantly higher in the transfused group $(2.7 \%)$ versus the not transfused group $(0.2 \%)(P=.02)$. Table 5 summarizes the complications that occurred within 90 days of the index surgery.

\section{DISCUSSION}

Significant blood loss in ASD surgery is not an infrequent occurrence and has the potential to cause irreversible end-organ damage, such a renal failure, cardiovascular events including stroke, and mortality. Perhaps a less important point in the mind of the surgeon, but nevertheless unavoidable in an era of healthcare cost containment, is the additional cost of care for a transfused patient including the cost of RBCs, FFP, platelets, and use of antifibrinolytics and cell salvage systems. ${ }^{26,27}$ Effectively predicting which patients are at an increased risk for sustaining greater intraoperative blood loss and requiring perioperative $\mathrm{RBC}$ transfusion arms surgeons with the knowledge needed for more optimized preoperative surgical planning, and enhanced utilization of healthcare resources. ${ }^{28,29}$ In this regard, we queried a large, single institution, multisurgeon database to determine the subset of variables that best predict intraoperative blood loss and transfusion requirement in patients undergoing long PSF for ASD. Using machine learning methodology, we found that number of levels fused, pelvic fixation, ASA score $>1$, 3-column osteotomy, and posterior column osteotomy were predictive of increased intraoperative blood loss, with the highest additional risk conferred by greater than 13 levels fused during surgery, and a preoperative hemoglobin $<13.6 \mathrm{~g} / \mathrm{dL}$. Greater than 13 levels fused, pelvic fixation, ASA score $>1$, 3-column osteotomy, and a history of hypertension were associated with the highest risk for requiring increased intraoperative RBC transfusion, whereas greater than 13 levels fused, pelvic fixation, and an ASA score $>2$ conferred the highest risk for requiring increased postoperative $\mathrm{RBC}$ transfusion.

Our results are consistent with previous studies using conventional regression methodology, which have reported associations between number of levels fused, pelvic fixation, 3-column osteotomy, and perioperative transfusion requirement. Basques et $\mathrm{al}^{30}$ looked at 4223 spine surgery patients using the American College of Surgeons National Surgical Quality Improvement Program (NSQIP) database and found that age $>60$ years, ASA score $>3$, greater than 3 levels fused, and operative time $>310$ minutes were predictive of increased RBC transfusion. The population of patients queried had undergone posterior primary lumbar fusion only. Berenholtz et al looked at 786 patients who underwent primary spine surgery, and found that age $>66$ years, and diabetes were independently associated with allogenic transfusion. ${ }^{31}$ Im- 
portantly, the patient population was relatively heterogeneous, as it included any case with a primary procedure code for spine surgery. In 112 patients who underwent revision lumbar decompression and posterior fusion, 1 study found that number of levels fused and preoperative hemoglobin were significant predictors of intraoperative blood loss. ${ }^{4}$

Predictors of blood loss and perioperative transfusion in patients undergoing ASD surgery has been less well studied, and there remains a paucity of data. White et $\mathrm{al}^{32}$ used NSQIP to evaluate 5805 patients who underwent long PSF and found that ASA $>3$, increasing construct length, fusion to the pelvis, and performance of osteotomy were independently associated with increased perioperative blood transfusion. From another analysis or the NSQIP, the same group found that patients with ASD with higher frailty scores had higher rates of blood transfusion. ${ }^{33}$ It stands to reason that the operative variables identified in this study to be predictive of increased blood loss and perioperative transfusion are those that signify a greater level of surgical complexity. Fusion constructs spanning a greater number of levels require wide exposure, and prolonged surgical duration. Similarly, performance of 3-column osteotomies is known to carry the potential for extensive blood loss. ${ }^{34,35}$

Although the question posed in our study is not a new one, the strength of this analysis is the use of conditional inference tree analysis, which allowed us to model complex interactions between variables. The 3 subpopulations generated to predict risk of intraoperative blood loss, by levels fused and types of procedures done, may assist surgeons in stratifying patients into groups of increasing risk. Surgical variables that characterized the highest risk group for intraoperative blood loss were patients who had over 13 levels fused, with performance of 3-column and/or posterior column osteotomies, and pelvic fixation. Further, we were able to characterize the incremental blood loss added by these procedures during surgery, with incorporation of pelvic fixation predicting an additional $20 \%$ blood volume lost, when performed for fusions $>13$ levels. Pelvic fixation has been shown to be independently associated with increased intraoperative and postoperative $\mathrm{RBC}$ transfusion in other studies in patients with ASD. ${ }^{36}$ Importantly, in the patient population studied, pelvic fixation denoted only iliac or S2-alar-iliac fixation, with the majority being the former. However, even for iliac fixation multiple techniques may be utilized including placing dual iliac screws, and a kickstand or flying buttress construct. These more complex constructs may be associated with increased operative time, and blood loss, which was not evaluated in the present study.

In terms of modifiable patient characteristics, we observed that a preoperative hemoglobin $<13.6 \mathrm{~g} /$ $\mathrm{dL}$ was predictive of a $14.6 \%$ increase in blood loss in cases where over 13 levels were fused, and an additional $0.25 \mathrm{U}$ of intraoperative $\mathrm{RBC}$ transfusion in cases where less than 6 levels were fused. Previous studies have demonstrated that decreased preoperative hemoglobin was predictive of increased length of hospital stay, and postoperative delirium. ${ }^{37}$ As the ASD surgical population is becoming progressively older, and surgeries are more commonly done tailored to age-appropriate alignment objectives, increased understanding of patient comorbidities and nutritional deficiencies that may be related to or causing the preoperative anemia are warranted. As most instances of preoperative anemia are not related to the spinal deformity being treated, it will most likely be present and persist after surgery. These data support the recommendation that preoperative anemia be investigated prior to surgery for its cause and appropriate treatment, to render the surgical patient "fit to fly."

The strengths of this study are the relatively homogenous population of patients with ASD with long fusion constructs and equivalent case complexity. The retrospective nature of our study could be perceived as a weakness; however, most data were collected prospectively. All patients were from a single institution and treated by surgeons who treat a large volume of adults with spinal deformity, which may limit the generalizability of our results. However, the exclusivity also conferred uniformity, and one might expect these types of surgical procedures to be performed at a tertiary care center by surgeons with similar experience.

\section{CONCLUSION}

Fusion spanning 13 vertebral levels or greater, ASA score $>1$, 3-column osteotomy, and pelvic fixation are consistent risk factors for increased percent blood volume lost and perioperative RBC transfusion. The best predictors for the subgroup at highest risk for intraoperative blood loss can be identified using conditional inference tree analysis; these included greater than 13 levels fused, pelvic 
fixation, ASA score $>1$, 3-column osteotomy, posterior column osteotomy, and preoperative hemoglobin $<13.6 \mathrm{~g} / \mathrm{dL}$. Patients who received major blood transfusion intraoperatively, as defined by $>4 \mathrm{U}$ RBCs $(10.8 \%$ of all patients), were significantly older (60.2 vs 41.8 years), had higher ASA (2.6 vs 2.4), underwent greater number of levels fused (13.2 vs 9.6), and had lower preoperative hemoglobin (13.1 vs 13.7) $(P<.0001$ for all). By multivariate regression analysis, patients with a preoperative hemoglobin $>13.0 \mathrm{~g} / \mathrm{dL}$ were less likely to require major blood transfusion (odds ratio: $0.52, P=.046$ ). An understanding of risk factors for blood loss and transfusion requirement for ASD surgery can facilitate preoperative surgical planning and perioperative management.

\section{REFERENCES}

1. Cha CW, Deible C, Muzzonigro T, Lopez-Plaza I, Vogt M, Kang JD. Allogeneic transfusion requirements after autologous donations in posterior lumbar surgeries. Spine. 2002;27(1):99-104.

2. Johnson RG, Murphy M, Miller M. Fusions and transfusions. An analysis of blood loss and autologous replacement during lumbar fusions. Spine. 1989;14(4):358-362.

3. Guay J, Haig M, Lortie L, Guertin MC, Poitras B. Predicting blood loss in surgery for idiopathic scoliosis. Can $J$ Anaesth. 1994;41(9):775-781.

4. Zheng F, Cammisa FP Jr, Sandhu HS, Girardi FP, Khan SN. Factors predicting hospital stay, operative time, blood loss, and transfusion in patients undergoing revision posterior lumbar spine decompression, fusion, and segmental instrumentation. Spine. 2002;27(8):818-824.

5. Cassinelli EH, Eubanks J, Vogt M, Furey C, Yoo J, Bohlman HH. Risk factors for the development of perioperative complications in elderly patients undergoing lumbar decompression and arthrodesis for spinal stenosis: an analysis of 166 patients. Spine. 2007;32:230-235.

6. Scheer JK, Smith JS, Schwab F, et al. Development of a preoperative predictive model for major complications following adult spinal deformity surgery. $J$ Neurosurg Spine. 2017;26(6):736-743.

7. Blood AG, Sandoval MF, Burger E, Halverson-Carpenter K. Risk and protective factors associated with surgical infections among spine patients. Surg Infect (Larchmt). 2017;18(3):234-249.

8. Kato S, Chikuda H, Ohya J, et al. Risk of infectious complications associated with blood transfusion in elective spinal surgery: a propensity score matched analysis. Spine J. 2016;16(1):55-60.

9. Triulzi DJ, Vanek K, Ryan DH, Blumberg N. A clinical and immunologic study of blood transfusion and postoperative bacterial infection in spinal surgery. Transfusion. 1992;32(6):517-524.

10. Zhang XN, Sun XY, Hai Y, Meng XL, Wang YS. Incidence and risk factors for multiple medical complications in adult degenerative scoliosis long-level fusion. J Clin Neurosci. 2008;54:14-19.

11. Veeravagu A, Patil CG, Lad SP, Boakye M. Risk factors for postoperative spinal wound infections after spinal decompression and fusion surgeries. Spine. 2009;34(17):1869-1872.

12. Aoude A, Nooh A, Fortin M, Aldebeyan S, Jarzem P, Quellet J. Incidence, predictors, and postoperative complications of blood transfusion in thoracic and lumbar fusion surgery: an analysis of 13,695 patients from the American College of Surgeons National Surgical Quality Improvement Program Database. Global Spine J. 2016;6(8):756-764.

13. Shander A, Hofmann A, Ozawa S, Theusinger OM, Gombolz H, Spahn DR. Activity-based costs of blood transfusions in surgical patients at four hospitals. Transfusion. 2010;50(4):753-765.

14. Samama CM. A direct antifibrinolytic agent in major orthopedic surgery. Orthopedics. 2004;27(6 suppl):s675-s680.

15. Zufferey P, Merquiol F, Laporte S, et al. Do antifibrinolytics reduce allogeneic blood transfusion in orthopedic surgery? Anesthesiology. 2006;105(5):1034-1046.

16. Kagoma YK, Crowther MA, Douketis J, Bhandari M, Eikelboom J, Lim W. Use of antifibrinolytic therapy to reduce transfusion in patients undergoing orthopedic surgery: a systematic review of randomized trials. Thromb Res. 2009;123(5):687-696.

17. Eubanks JD. Antifibrinolytics in major orthopaedic surgery. J Am Acad Orthop Surg. 2010;18(3):132-138.

18. Liang J, Shen J, Chua S, et al. Does intraoperative cell salvage system effectively decrease the need for allogeneic transfusions in scoliotic patients undergoing posterior spinal fusion? A prospective randomized study. Eur Spine J. 2015;24(2):270-275.

19. Shen J, Liang J, Yu H, Qiu G, Xue X, Li Z. Risk factors for delayed infections after spinal fusion and instrumentation in patients with scoliosis. J Neurosurg Spine. 2014;21(4):648-652.

20. Hothorn T, Hornik K, Zeileis A. Unbiased recursive partitioning: a conditional inference framework. J Comput Graph Stat. 2006;15(3):651-674.

21. Tanadini LG, Steeves JD, Hothorn T, et al. Identifying homogeneous subgroups in neurological disorders: unbiased recursive partitioning in cervical complete spinal cord injury. Neurorehabil Neural Repair. 2014;28(6):507-515.

22. Subramaniam S, Aalberg JJ, Soriano RP, Divino CM. New 5-factor modified frailty index using American College of Surgeons NSQIP data. J Am Coll Surg. 2018;226(2):173-181.e8.

23. Chimukangara M, Helm MC, Frelich MJ, et al. A 5-item frailty index based on NSQIP data correlates with outcomes following paraesophageal hernia repair. Surg Endosc. 2017;31(6):2509-2519.

24. Mirza SK, Deyo RA, Heagerty PJ, Turner JA, Lee LA, Goodkin R. Towards standardized measurement of adverse events in spine surgery: conceptual model and pilot evaluation. BMC Musculoskelet Disord. 2006;7:53.

25. Mirza SK, Deyo RA, Heagerty PJ, et al. Development of an index to characterize the "invasiveness" of spine surgery: validation by comparison to blood loss and operative time. Spine. 2008;33(24):2651-2661.

26. Theusinger OM, Spahn DR. Perioperative blood conservation strategies for major spine surgery. Best Pract Res Clin Anaesthesiol. 2016;30(1):41-52.

27. Blanchette CM, Wang PF, Joshi AV, Asmussen M, 
Saunders W, Kruse P. Cost and utilization of blood transfusion associated with spinal surgeries in the United States. Eur Spine J. 2007;16(3):353-363.

28. Puvanesarajah V, Rao SS, Hassanzadeh H, Kebaish, KM. Determinants of perioperative transfusion risk in patients with adult spinal deformity. J Neurosurg Spine. 2018;28(4):429435.

29. Yoshida G, Hasegawa T, Yamato Y, et al. Predicting perioperative complications in adult spinal deformity surgery using a simple sliding scale. Spine. 2018;43(8):562-570.

30. Basques BA, Anandasivam NS, Webb ML, et al. Risk factors for blood transfusion with primary posterior lumbar fusion. Spine. 2015;40(22):1792-1797.

31. Berenholtz SM, Pronovost PJ, Mullany D, et al. Predictors of transfusion for spinal surgery in Maryland, 1997 to 2000. Transfusion. 2002;42(2):183-189.

32. White SJW, Cheung ZB, Ye I, et al. Risk factors for perioperative blood transfusions in adult spinal deformity surgery. World Neurosurg. 2018;115:e731-e737.

33. Level DM, Lee NJ, Kothari P, et al. Frailty index is a significant predictor of complications and mortality after surgery for adult spinal deformity. Spine. 2016;41(23):e1394 e1401.

34. Boachie-Adjei O, Bradford DS. Vertebral column resection and arthrodesis for complex spinal deformities. $J$ Spinal Disord. 1991;4(2):193-202.

35. Suk SI, Kim JH, Kim WJ, Lee SM, Chung ER, Nah KH. Posterior vertebral column resection for severe spinal deformities. Spine. 2002;27(21):2374-2382.
36. Kothari P, Somani S, Lee NJ, et al. Thirty-day morbidity associated with pelvic fixation in adult patients undergoing fusion for spinal deformity: a propensity-matched analysis. Global Spine J. 2017;7(1):39-46.

37. Elsamadicy AA, Adogwa O, Ongele M, et al. Preoperative hemoglobin level is associated with increased health care use after elective spinal fusion ( $\geq 3$ levels) in elderly male patients with spine deformity. World Neurosurg. 2018;112:e348e354.

Disclosures and COI: The authors received no funding for this study and report no conflicts of interest.

Corresponding Author: Tina Raman, MD, Spine Research Center, NYU Langone Orthopedic Hospital, 306 East 15th St, New York, NY 10003. Phone: (212) 598-6000; Email: tina.raman@ nyulangone.org.

Published 29 February 2020

This manuscript is generously published free of charge by ISASS, the International Society for the Advancement of Spine Surgery. Copyright (C) 2020 ISASS. To see more or order reprints or permissions, see http://ijssurgery.com. 